\title{
Mining
}

http://dx.doi.org/10.1590/0370-44672015690155

\author{
Fernanda Gontijo Fernandes \\ Geoestatística \\ Vale Fertilizantes - Gerência de Avaliação de \\ Recursos Minerais \\ Belo Horizonte - Minas Gerais - Brasil \\ fernanda.gontijo@valefert.com \\ Ivo Eyer Cabral \\ Professor Adjunto \\ Universidade Federal de Ouro Preto - UFOP \\ Escola de Minas \\ Departamento de Engenharia de Minas \\ Ouro Preto - Minas Gerais - Brasil \\ cabralmg@uol.com.br
}

\section{Regression model utilization to estimate the mass recovery of a phosphate mine in Brazil}

\begin{abstract}
The construction of block models with an estimation of grades in situ is a common practice throughout resource evaluation. However, this information is not enough to understand the behavior of the ore in the beneficiation process. Geometallurgy proposes the addition of the ore's metallurgical behavior in the block model, making it more dependable and adhering when it comes to production capacity, which generates financial earnings and brings risks down. Mass recovery is an important metallurgical variable for economic and mine planning. This is often underused, due to the lack of data, making it hard to use in the planning process. In order to achieve better use of the data available, the multiple regression analysis technique was used so as to develop a statistic model that would relate the mass recovery with the in situ grades, allowing that deposit regions with no available metallurgical information have an estimation of this variable's values.
\end{abstract}

Keywords: geometallurgy; multiple regression analysis; mass recovery; phosphate.

\section{Introduction}

Geometallurgy is a discipline that aims at figuring out the link between geology and ore behavior throughout the beneficiation process. In some mines such as the phosphate ones, which is the focus of this study, it is as or more important to know the ore's behavior in the process than to know its in situ grade. This is because it is common to observe samples with a high $\mathrm{P}_{2} \mathrm{O}_{5}$ grade that have flotation problems caused by the presence of contaminants elements, and samples with moderate grade that show better reaction during the process due to a lack of ele-

\section{Materials and methods}

Samples obtained from drill holes available in the mine have been used for the development of this study. Initially, all samples from the area mineralized in phosphate were identified. Such identification was made possible through chemical analysis of a part of the available drill holes by use of the X-Ray Fluorescence technique. All mineralized intervals were again sampled and submitted to a characterization process, detailed hereinafter.

The sample was weighed, milled in a ball mill and then submitted to mag- ments which negatively impact on beneficiation. However, flotation tests take long and are costly, which makes it difficult to chemically analyze each sample and also submit them to beneficiation tests, making this kind of information scarce and hardly ever used.

The multiple regression analysis (Draper e Smith, 1966) enables the finding of the statistical relationship between the interest dependent variable and two or more independent variables. In this study, the objective was to develop a model that could estimate the mass recovery of the

netic separation, in which the magnetic part was discarded. The non magnetic part passed through the hydrocyclone and the overflow was discarded. The underflow was dried, weighed and homogenized. After homogenization, two aliquots of approximately $3000 \mathrm{~g}$ were extracted. These aliquots were attritioned and were again put in the hydrocyclone, in which the overflow was discarded and the underflow was filtered, dried and homogenized. After the homogenization, three aliquots of approximately $1000 \mathrm{~g}$
$\mathrm{P}_{2} \mathrm{O}_{5}$ concentrate in relation to the $\mathrm{ROM}$ mass (dependent variable that from this point on will be named mass recovery) in samples with information only on in situ grades (independent variables), which correspond to most samples of the phosphate mine under study. Therefore, the constructed regression model enables the understanding of the relation between the chemistry of the deposit and the process results, achieving the goal of the geometallurgical study and allowing a spatial estimation of this variable, leading to a more efficient mine planning. each were taken out for the flotation tests, along with an aliquot of nearly $200 \mathrm{~g}$ that was sent to chemical analysis after quartering and pulverization of approximately $25 \mathrm{~g}$ of the material. The chemical analysis of this aliquot informs the grades of $\mathrm{Al}_{2} \mathrm{O}_{3}, \mathrm{CaO}, \mathrm{Fe}_{2} \mathrm{O}_{3}, \mathrm{MgO}$, $\mathrm{P}_{2} \mathrm{O}_{5}, \mathrm{SiO}_{2}$ and $\mathrm{TiO}_{2}$ in the flotation feed.

The depressor used in the flotation tests was corn starch, which is used in all igneous phosphate Brazilian mines (Guimarães et al., 2005), the $\mathrm{pH}$ modifier was caustic soda and the collectors were 
hydrogenated soybean oil and sulphosuccinate. The dosages and the manner of preparation of the reagents, as well as the stages of realization of the flotation tests, are not described in this article due to an NDA demanded by the company that supplied the data. Once the flotation test was done with, the obtained concen-

\section{Results and discussion}

The multiple regression model was made up of 342 samples that contained information about all variables needed for the development of the proposed study. According to Williams and Richardson (2004), the number of metallurgical tests needed for the development of a geometallurgical mapping varies between 100 and 300 . Such evidence shows that the database used is robust.

The Kruskal Wallis test (Siegel trate was weighed in order to enable the calculation of the mass recovery and, right after, it was submitted to chemical analysis so as to verify if the obtained $\mathrm{P}_{2} \mathrm{O}_{5}$ grade corresponded to the product's specification $(35.8 \%)$. In case the $\mathrm{P}_{2} \mathrm{O}_{5}$ grade did not meet desirable levels, the dosage of the collectors was adjusted and new flotation tests were run by use of the two remaining aliquots prepared for flotation.

In order to perform the proposed study, the chemical analysis of the samples was paired with the mass recovery data, which originated the database used to develop the regression model. and Castellan Jr., 2006) was run to evaluate if the different lithologies came from the same population, or in other words, if they behave the same way in the process when it came to mass recovery. The conclusion was that the metallurgical behavior evaluated was not impacted by this factor, which led to the construction of a single model for all lithotypes.

Equation 1 shows the model constructed to estimate the mass recovery.
All independent variables were statistically significant to level $5 \%$ and the suppositions of linearity, homoscedasticity and independency were confirmed, but the normality of the residuals was not obtained. However, samples with 200 or more observations, which is the case in this study, may have the effects of the non-normality overlooked (Hair et al, 2009), considering that the size of the sample impacts directly in the power of the statistic tests.

$$
\text { Mass Recovery }(\%)=8.56+\left(1.67 * P_{2} O_{5 R O M}\right)-\left(0.13 * \mathrm{Fe}_{2} \mathrm{O}_{3 R O M}\right)-\left(0.17 * \mathrm{TiO}_{2 R O M}\right)-\left(0.14 * \mathrm{SiO}_{2 R O M}\right)
$$

The interpretation of equation 1 shows that an increase of $1 \%$ in the $\mathrm{P}_{2} \mathrm{O}_{5}$ grade leads to an increase of $1.67 \%$ in the mass recovery. On the other hand, it has been observed that an increase of $1 \%$ in the $\mathrm{Fe}_{2} \mathrm{O}_{3}, \mathrm{TiO}_{2}$ and $\mathrm{SiO}_{2}$ grade in $\mathrm{ROM}$ leads to a reduction of $0.13 \%, 0.17 \%$ and $0.14 \%$ of such variable, respectively, which reflects the behavior observed during the ore beneficiation under study.

The scatter plot presented in figure 1 illustrates the correlation of $92 \%$

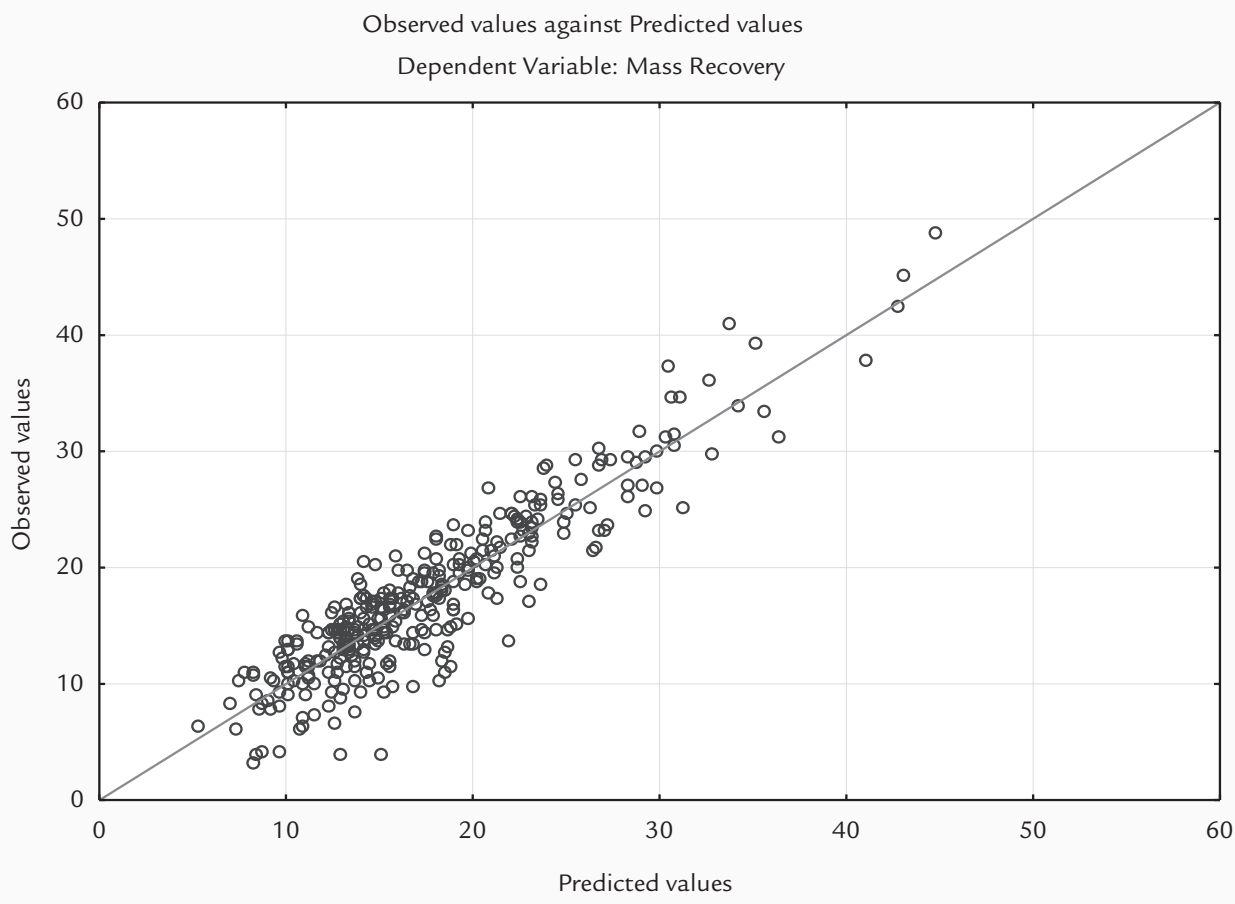

As all estimation methods, the regression analysis has an error associated to its predictions and it is the user's responsibility to evaluate whether this is or not acceptable. Previous studies made in the mine under study revealed that the relative errors of chemical analysis by X-Ray between the predicted values and the real mass recovery values. The average relative error obtained by the use of equation 1 was $4.98 \%$ and the average residual was zero, which indicates the quality of the constructed model.

Figure 1

Mass recovery observed values against predicted values by the model.

Fluorescence reach up to $10 \%$, so the errors obtained through the use of the model in question can be considered acceptable. 


\section{Conclusion}

The information generated based on regression models built can be used in the geostatistical study of the deposit in a way which besides the in situ estimated grades for each sample or block, there can also be an estimation of the mass recovery.

\section{References}

Adding this information to the block model leads to a better economic planning since there is a prevision of the amount of product obtained after flotation.

It is important to reinforce that the models herein presented are valid only for mass recovery estimation in this phosphate mine, and that for other mines, there must be developed a similar study aiming at the construction of an adequate model for their chemical and geological characteristics.

DRAPER, N. R., SMITH, H. Applied regression analysis. New York: John Wiley \& Sons, Inc., 1966. p. 44-81.

GUIMARÃES, R. C., ARAÚJO, A. C., PERES, A. E. C. Reagents in igneous phosphate ores flotation. Minerals Engineering, v.18, p. 199-204, 2005.

HAIR, J. F., ANDERSON, R. E., TATHM, R. L., BLACK, W. C., BABIN, B. J. Análise multivariada de dados. New Jersey: Prentice Hall, 2009. p.83.

SIEGEL, S., CASTELLAN JR., N. J. Estatística não-paramétrica para ciências do comportamento. (2nd. Ed.). Porto Alegre: Artmed, 2006. p. 235-245.

WILLIAMS, S. R., RICHARDSON, J. M. Geometallurgical mapping: a new approach that reduces technical risk. ANNUAL MEETING OF THE CANADIAN MINERAL PROCESSORS, 36. Proceedings. Paper 16, 2004.

Received: 21 August 2013 - Accepted: 30 April 2014. 